\title{
BMJ Open Association between community management of pneumonia and diarrhoea in high-burden countries and the decline in under-five mortality rates: an ecological analysis
}

\author{
Cynthia Boschi-Pinto, ${ }^{1,2}$ Thandassery Ramachandran Dilip, ${ }^{1}$ Anthony Costello ${ }^{1}$
}

To cite: Boschi-Pinto C, Dilip TR, Costello A. Association between community management of pneumonia and diarrhoea in high-burden countries and the decline in under-five mortality rates: an ecological analysis. BMJ Open 2017;7: e012639. doi:10.1136/ bmjopen-2016-012639

- Prepublication history and additional material is available. To view please visit the journal (http://dx.doi.org/ 10.1136/bmjopen-2016012639)

Received 16 May 2016 Revised 21 October 2016 Accepted 25 October 2016

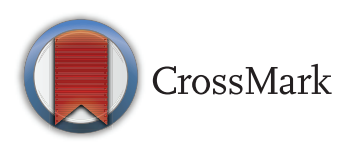

${ }^{1}$ Department of Maternal Newborn Child and Adolescent Health, World Health Organization, Geneva, Switzerland

${ }^{2}$ Instituto de Saúde Coletiva, Universidade Federal Fluminense, Niteroi, Brazil

Correspondence to Dr Cynthia Boschi-Pinto; pintoc@who.int

\section{ABSTRACT}

Objective: The objective of the paper is to explore if the adoption of national policies to use communitybased health providers for the management of pneumonia and diarrhoea is associated with the decline in under-five mortality, including achievement of the Millennium Development Goal (MDG) 4 target, in high-burden countries.

Setting: This country level analysis covers 75 highburden low-income and middle-income countries which accounted for $98 \%$ of the 5.9 million global under-five deaths in 2015. One-fourth of these deaths were due to pneumonia and diarrhoea.

Methods: $\chi^{2}$ tests and multiple regression analysis were used to examine the association between reduction in under-five mortality rates and community case management of pneumonia and diarrhoea by adjusting for the influence of other possible determinants.

Participants: No patient or population interviewed/ examined for this analysis. Countries were the unit of analysis.

Interventions: Community case management (CCM) of pneumonia and diarrhoea policies.

Outcome measures: Changes in under-five mortality rates over time.

Results: Countries that had adopted both CCM policies were three times more likely to achieve the MDG4 target than countries that did not have both policies in place. This association was further confirmed by the multivariate analysis ( $\beta$ coefficient $=10.4 ; 95 \% \mathrm{Cl} 2.4$ to $18.5 ; \mathrm{p}$ value $=0.012$ ).

Discussion: There is a statistically significant association between adoption of CCM policies for treatment of pneumonia and diarrhoea and the rate of decline in child mortality levels. It is important to promote CCM in countries lagging behind to achieve the new target of 25 or fewer deaths per 1000 live births by 2030 .

\section{INTRODUCTION}

At the end of 2015, the Millennium Development Goals (MDGs) era concluded and the international community moved to

\section{Strengths and limitations of this study}

- The existing evidence of the impact of community-based management of pneumonia and diarrhoea on child mortality is mainly based on implementation research at the national and regional levels. This study shows the statistical association between the adoption of national policies to use community-based health providers for the management of pneumonia and diarrhoea and the decline in under-five mortality at the global level.

- This study uses new data from the biannual Global Maternal Newborn Child and Adolescent Health Policy Indicators Survey undertaken by the WHO and recent estimates of under-five mortality rates from 1990 to 2015.

- The policy survey data used only provide information on the existence of a national policy/ statement and not on the rigorousness or process of its implementation.

- The ecological study design used in this analysis does not go beyond the testing of this association and therefore does not imply any causal relationship.

adopt the Sustainable Development Goals (SDGs). The target of reducing under-five mortality by two-thirds between 1990 and 2015 achieved substantial progress-a 53\% decline in under-five mortality rates from 1990 (91 deaths per 1000 live births) to 2015 (43 deaths per 1000 live births), corresponding to a fall from 12.7 million deaths in 1990 to 5.9 million deaths in 2015. The MDG4 target was attained by 62 of the 195 countries with available mortality estimates. Of these, 24 are low-income and lower-middle income countries. An additional 74 countries reduced their under-five mortality rates by at least half. ${ }^{1}$

Despite this progress, we still face a big challenge to reach the new SDG target of 25 or fewer deaths per 1000 live births by 2030 . We need to learn lessons from MDG 
successes and failures and the pattern and distribution of the main causes of death can provide insightful hints. Estimates for 2015 show that about one-quarter of the global under-five deaths are due to pneumonia and diarrhoea. ${ }^{2}$ Notably, nearly $40 \%$ of the 4 million fewer under-five deaths between 2000 and 2015 were due to reductions in deaths caused by these two conditions.

Community case management (CCM) of diseases is effective in addressing inequities in access to medical care where the health system coverage is inadequate. ${ }^{3} 4$ The WHO and UNICEF support the adoption of CCM in such circumstances, as they improve coverage of key child survival interventions, therefore contributing to mortality reduction. ${ }^{5}{ }^{6} \mathrm{CCM}$ strategy has been adopted by countries with high child mortality. ${ }^{78}$

Our interest in the accelerated progress towards attainment of MDG4 among high-burden countries that implemented CCM for both pneumonia and diarrhoea led us to examine the association between the existence of national policies to use community-based health providers for the management of pneumonia and diarrhoea and the decline in child mortality, including the achievement of the MDG4 target in 75 high-burden low-income and middle-income countries.

\section{METHODS}

We used an ecological study design to explore the association between adoption of CCM policies for the management of pneumonia and diarrhoea and changes in under-five mortality rates in high-burden countries. High-burden countries were those identified by the Commission on Information and Accountability (CoIA) for special attention, where $98 \%$ of global child deaths occur. ${ }^{9}$ Progress in reduction of under-five mortality and achievement of MDG4 were calculated based on the under-five mortality rates for the years 1990 and 2015; data were obtained from the UN Inter-agency Group for Child Mortality Estimation (UN-IGME) report on levels and trends in child mortality. ${ }^{1}$ Information on existence of national policies to use community-based health providers for management of diarrhoea and pneumonia was mostly taken from the biannual Global Maternal Newborn Child and Adolescent Health (MNCAH) Policy Indicators Survey ${ }^{9}$ undertaken by the WHO. The survey had separate questions for diarrhoea and pneumonia on "Has the country a national policy/policy statement on the use of community-based health providers to deliver child health interventions at home and/or in the community?", which was combined to arrive at the policy indicator: CCM for both diarrhoea and pneumonia. Of the 75 high priority countries, the Democratic People's Republic of Korea was excluded as the country did not participate in the policy survey. Non-response to the respective questions in the MNCAH policy indicator survey meant that information on CCM policy for pneumonia for three countries (Equatorial Guinea, Kenya and Mauritania) and CCM policy for diarrhoea for two countries (Ghana and Mauritania) were obtained from comparable indicators provided in the UNICEF survey report on government policy and implementation status of CCM for diarrhoea, pneumonia and malaria in 44 sub-Saharan African countries. ${ }^{10}$

The UN-IGME median estimates of child mortality were used to examine changes in child mortality levels between 1990 and 2015, and identify countries that achieved MDG4. We used Pearson $\chi^{2}$ to test the association between the existence of both CCM policies and achievement of MDG4. We also explored the relative progress in decline in child mortality levels between countries with both policies and those without one or both policies. For that, countries were ranked based on the level of child mortality in 1990 and 2015. Differences in ranks at baseline and final assessment were obtained. On the basis of these differences, countries were classified into three groups: ${ }^{1}$ countries whose position improved by 10 or more ranks; ${ }^{2}$ countries whose position declined by 10 or more ranks; and ${ }^{3}$ countries whose position did not vary by more than 10 ranks. The 10-rank cut-off was arbitrarily chosen with an ultimate aim to examine if CCM policy could be associated with sizable leaps in terms of decline in child mortality in comparison with their counterparts.

Finally, we tested the association between countries where CCM policy was available for both pneumonia and diarrhoea and percentage changes in under-five mortality rates between 1990 and 2015 using both univariate and multivariate regression analysis. The latter was adjusted for percentage changes in gross domestic product (GDP) per capita between 1990 and 2015, current GDP per capita, (2015), percentage changes in number of physicians per 1000 population between 1990 and 2013, number of physicians per 1000 population in 2013, percentage changes in primary school enrolment of women between 1990 and 2010, primary school enrolment of women in 2010, percentage changes in hospital beds per 1000 population between 1990 and 2012, hospital beds per 1000 population in 2012 and coverage level of Haemophilus influenzae type B (Hib) vaccine in 2015. Except for availability of CCM policy, all other covariates were used as continuous variables. Bed-population ratio was used as a proxy for health facility coverage and physician-population ratio was chosen instead of closely-related nurse-population ratio due to paucity of data. No categorisation or transformation was performed. We used interpolation and extrapolation to calculate missing values within the indicator range. A single data file was created using CCM information from the Global MNCAH Policy Indicators Survey, under-five mortality rates from the UN-IGME and values for independent variables from different sources. Details on sources of information are shown in the web appendix. Analysis was performed using STATAV.11.

\section{Patient involvement}

This is an ecological study in which analysis of routine aggregated data at the national level was performed; no individual patient data were included. 


\section{RESULTS}

\section{National policies}

The national policy on CCM for diarrhoea was reported to be present in $84 \%$ (62 countries) and for pneumonia in $59 \%$ ( 44 countries) of the 74 high priority countries analysed. As expected, countries with a CCM policy for pneumonia have also adopted a similar policy for diarrhoea. Hence, the share of countries with a CCM policy for both diarrhoea and pneumonia was 59\%. The distribution of countries, according to their proportional reduction in under-five mortality and the adoption of CCM policies on pneumonia and diarrhoea, is shown in figure 1.

\section{MDG4 target success}

The MDG4 target of two-thirds reduction in under-five mortality was attained by $17(39 \%)$ of the 44 countries that adopted both policies and by only $5(17 \%)$ of the remaining 30 countries where CCM policy was not available for both pneumonia and diarrhoea (Pearson $\chi^{2}=4.12 ; p$ value $\left.=0.042\right)$. Similarly, countries that had adopted both CCM policies were more likely to improve their ranking in child mortality level by 10 positions (Pearson $\chi^{2}=6.96 ; p$ value $=0.031$ ) than countries that did not have both policies (table 1). The unadjusted analysis of the association between countries where CCM policy is made available for both pneumonia and diarrhoea and percentage changes in under-five mortality rates between 1990 and 2015 provided a $\beta$-coefficient of 12.2 (95\% CI 4.4 to 20.0 ; p value $=0.003)$, suggesting that having adopted the two CCM policies might have contributed to a $12 \%$ decline in U5MRs over that period in time (table A1 in web appendix2).

\section{Adjustment for confounding factors}

Clearly, the association between adoption of a national policy and an outcome for mortality reduction could be confounded by economic, educational, health, infrastructural and social trends. After adjustment for the potential confounders listed above, the association between success in the decline of child mortality and CCM national policies was further confirmed by the multivariate analysis ( $\beta$-coefficient $=10.45 ; 95 \%$ CI 2.41 to 18.48; $\mathrm{p}$ value $=0.012$ ) (table A2 in web appendix2).

\section{DISCUSSION}

The positive impact of the CCM approach in childhood pneumonia mortality in developing countries has already been confirmed in earlier meta-analysis. ${ }^{11-13}$ This ecological study suggests that countries that have adopted this approach for treatment of diarrhoea and pneumonia may have benefited from a further decline in child mortality levels than their counterparts. The observed association between the adoption of the two

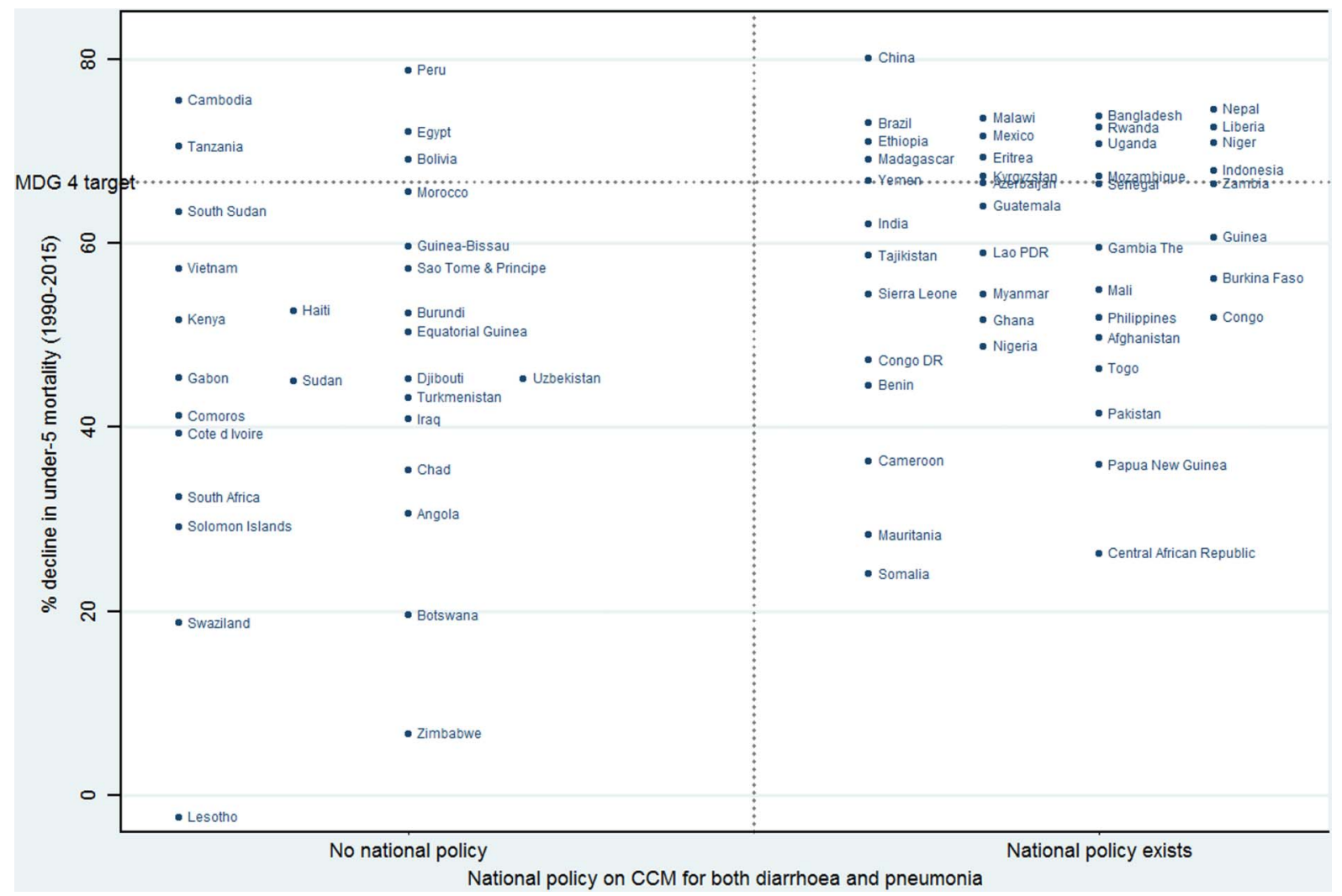

Figure 1 Distribution of 74 high-burden low-income and middle-income countries according to their proportional decline in under-five mortality between 1990 and 2015 and policy status on CCM for both diarrhoea and pneumonia. CCM, community case management. 
Table 1 Association between adoption of national policies on CCM for both pneumonia and diarrhoea and changes in total under-five mortality level between 1990 and 2015 in 74 high-burden low-income and middle-income countries

National policy on CCM for both diarrhoea and pneumonia

\begin{tabular}{lll}
$\begin{array}{l}\text { Percentage of countries with } \\
\text { both policies }(\mathrm{N}=44)\end{array}$ & $\begin{array}{l}\text { Percentage of countries without } \\
\text { both policies }^{*}(\mathrm{~N}=30)\end{array}$ & $\begin{array}{l}\text { Pearson } \chi^{2} \text { value } \\
(\mathrm{p} \text { value })\end{array}$ \\
\hline
\end{tabular}

\begin{tabular}{|c|c|c|c|}
\hline \multicolumn{4}{|c|}{ Achievement of MDG4 target } \\
\hline Target not achieved & $61(27)$ & $83(25)$ & $4.12(0.042)$ \\
\hline Target achieved & $39(17)$ & $17(5)$ & \\
\hline \multicolumn{4}{|c|}{ Relative ranking in child mortality (1990 and 2015) } \\
\hline $\begin{array}{l}\text { Rank decreased by } \\
10 \text { positions }\end{array}$ & $16(7)$ & $43(13)$ & $6.96(p=0.031)$ \\
\hline $\begin{array}{l}\text { Rank within } \pm 10 \\
\text { positions }\end{array}$ & $55(24)$ & $40(12)$ & \\
\hline $\begin{array}{l}\text { Rank improved by } 10 \\
+ \text { positions }\end{array}$ & $30(13)$ & $17(5)$ & \\
\hline Total & $100(44)$ & $100(30)$ & \\
\hline
\end{tabular}

CCM policies and reductions in U5MR may not be in any way causal. Nonetheless, we wish to flag the hypothesis of a plausible correlation for prospective analysis.

Confounders may underlie this relationship. Socioeconomic improvements are likely to be one of the potential confounders of this association. Adjustments by GDP per capita and female school enrolment did not significantly change the magnitude of the association between CCM policies and relative mortality decline. Use of vaccines against Streptococcus pneumoniae, Hib and Rotavirus substantially reduces the disease burden caused by these infectious agents. ${ }^{14-16}$ Only recently have these vaccines been introduced in countries. We have controlled for the recent coverage of Hib vaccine, which, of the three, is the one more broadly implemented in countries. A strong health system that is able to support national CCM programmes by providing training, supervision, supplies and other commodities is a key requirement for the success of such programmes. ${ }^{17} 18$ We have tried to at least partly account for this by adjusting for changes in bed/population ratio and physician/ population ratio in the study period. These covariates were used as proxy indicators of the performance and coverage of the health system, respectively, in the multivariate analysis. Adjustment for confounders did not change the significance of the statistical association between adoption of CCM policies by countries and reduction in under-five mortality rates ( tables A1 and A2 in web appendix2).

The strength of the health systems, as well as the policy implementation process, is essential for the attainment of successful outcomes. Contextual factors such as the country's history of primary healthcare and CHW programmes, as well as the engagement and leadership of key actors during the process of implementation of CCM policies in different settings, play essential roles in the effective adoption of such policies. ${ }^{8} 1920$ It is also generally agreed that the stringency in implementation of the CCM policy is not uniform due to intercountry variations in community health worker-population ratio and in readiness and availability of medicines and other commodities for CCM programmes. ${ }^{21}$ An inherent data limitation arises from the fact that the Global MNCAH Policy Indicator Survey only provides information on the existence of a national policy/statement and not on the rigorousness, process and challenges during its implementation. If we are to achieve the new target of 25 or fewer deaths per 1000 live births by 2030, we must advocate CCM in high-priority countries which are lagging in implementation of such policies. In countries implementing CCM, a focus on the quality of services through better outreach of community health workers, improved availability of essential medicines and of other commodities, and better referral link between community health providers and hospitals will be essential to achieve the ambitious SDG targets. Ensuring countries have clear national policies is an important start. Ensuring that countries have clear national policies is an important start.

Acknowledgements The authors thank Dr Matthews Mathai and Dr Shamim Qazi for their valuable reviews and for the comments provided.

Contributors The authors bring a combination of expertise in epidemiology, demography, interventions, policies, public health and advocacy. CBP conceptualised the paper. TRD performed the statistical analysis. Both CBP and TRD wrote the first draft of the manuscript and AC contributed intellectual content and critical revisions to the manuscript. All authors approved the final manuscript. CB-P is the guarantor.

Funding This research received no specific grant from any funding agency in the public, commercial or not-for-profit sectors.

Disclaimer The authors are staff members of the WHO. The authors alone are responsible for the views expressed in this publication and they do not necessarily represent the decisions or policies of the WHO.

Competing interests None declared.

Provenance and peer review Not commissioned; externally peer reviewed.

Data sharing statement All data are available in public domain. Sources can be found in Web Appendix 1. 
Open Access This is an Open Access article distributed in accordance with the Creative Commons Attribution Non Commercial (CC BY-NC 4.0) license, which permits others to distribute, remix, adapt, build upon this work noncommercially, and license their derivative works on different terms, provided the original work is properly cited and the use is non-commercial. See: http:// creativecommons.org/licenses/by-nc/4.0/

\section{REFERENCES}

1. UNICEF/WHO/The World Bank/United Nations Population Division. Levels \& Trends in Child Mortality Report 2015. Estimates developed by the UN Inter-agency Group for Child Mortality Estimates.

2. World Health Organization. Global Health Observatory [Internet]. http://www.who.int/entity/healthinfo/global_burden disease/ estimates_child_cod_2015/en/index.html

3. Waters D, Theodoratou E, Campbell H, et al. Optimizing community case management strategies to achieve equitable reduction of childhood pneumonia mortality: an application of Equitable Impact Sensitive Tool (EQUIST) in five low- and middle-income countries. $J$ Glob Health 2012;2:020402.

4. Oliphant NP, Muñiz M, Guenther T, et al. Multi-country analysis of routine data from integrated community case management (iCCM) programs in sub-Saharan Africa. J Glob Health 2014;4:020408.

5. WHO/UNICEF Joint Statement Clinical Management of Acute Diarrhea. WHO/FCH/CAH/04.07 UNICEF/PD/Diarrhea/01. Geneva, New York: WHO and UNICEF, 2004:8.

6. WHO/UNICEF Joint Statement Management of Pneumonia in Community Settings. WHO/FCH/CAH/04.06 UNICEF/PD/ Pneumonia/01. Geneva, New York: WHO and UNICEF, 2004:8.

7. World Health Organization. Selected policies for reducing under 5 year child mortality in low and middle income countries [Internet]. http://www.who.int/maternal_child_adolescent/documents/countries/ indicators/3_child_health_policy_indicators.pdf?ua=1 (accessed 15 Sep 2015).

8. de Sousa A, Tiedje KE, Recht J, et al. Community case management of childhood illnesses: policy and implementation in Countdown to 2015 countries. Bull World Health Organ 2012;90:183-90.

9. Commission on Information and Accountability for Women's and Children's Health. Keeping promises, measuring results. Geneva: WHO, 2011.
10. UNICEF. Community case management of diarrhoea, malaria and pneumonia: tracking science to policy and practice in sub-Saharan Africa. New York: United Nations Children's Fund (UNICEF), 2012.

11. Sazawal S, Black RE. Effect of pneumonia case-management on mortality in neonates, infants, and preschool children: a meta-analysis of community-based trials. Lancet Infect Dis 2003;3:547-56.

12. Theodoratou E, Al-Jilaihawi S, Woodward F, et al. The effect of case management on childhood pneumonia mortality in developing countries. Int J Epidemiol 2010;39:i155-171.

13. Das JK, Lassi ZS, Salam RA, et al. Effect of community based interventions on childhood diarrhea and pneumonia: uptake of treatment modalities and impact on mortality. BMC Public Health 2013;13(Suppl 3):S29.

14. World Health Organization. WHO position paper on Haemophilus influenzae type b conjugate vaccines. (Replaces WHO position paper on Hib vaccines previously published in the Weekly Epidemiological Record. Wkly Epidemiol Rec 2006;81: 445-52.

15. Theodoratou E, Johnson S, Jhass A, et al. The effect of Haemophilus influenzae type $b$ and pneumococcal conjugate vaccines on childhood pneumonia incidence, severe morbidity and mortality. Int J Epidemiol 2010;39(Suppl 1):i172-85.

16. WHO. Pneumococcal vaccines: WHO position paper. Wkly Epidemiol Rec 2012;14:129-44.

17. CORE Group/Save the Children/BASICS/MCHIP. Community case management essentials: treating common childhood illnesses in the community. Washington, DC: A Guide for Program Managers 2010.

18. Haines A, Sanders D, Lehmann U, et al. Achieving child survival goals: potential contribution of community health workers. Lancet 2007;369:2121-31.

19. Bennett S, George A, Rodriguez D, et al. Policy challenges facing integrated community case management in Sub-Saharan Africa. Trop Med Int Health 2014;19:872-82.

20. George A, Young M, Nefdt R, et al. Community health workers providing government community case management for child survival in sub-Saharan Africa: who are they and what are they expected to do?. Am J Trop Med Hyg 2012;87(Suppl 5):85-91.

21. UNICEF/WHO. Countdown to 2015: A Decade of Tracking Progress for Maternal, Newborn and Child Survival The 2015 Report. Washington, DC. 2015. 